\title{
A prospective study of abdominal wall endometriomas: a review of 16 cases
}

\author{
Y. Lakshmi Nalini' ${ }^{1 *}$, Manipal Kumar Puvvala², A. Sarath Chandra², Rajalingam²
}

\begin{abstract}
${ }^{1}$ Department of Obstetrics and Gynecology, ${ }^{2}$ Department of General Surgery, MallaReddy Institute of Medical Sciences, Hyderabad, Telangana, India
\end{abstract}

Received: 14 May 2017

Accepted: 20 May 2017

\section{*Correspondence:}

Dr. Y. Lakshmi Nalini,

E-mail: ylakshminalini@gmail.com

Copyright: () the author(s), publisher and licensee Medip Academy. This is an open-access article distributed under the terms of the Creative Commons Attribution Non-Commercial License, which permits unrestricted non-commercial use, distribution, and reproduction in any medium, provided the original work is properly cited.

\section{ABSTRACT}

Background: Endometriosis is a disorder in which an ectopic endometrial tissue grows outside the uterine cavity. The ectopic endometrium in abdominal wall is called as abdominal wall endometriosis (AWE). AWE is a very rare condition and exact incidence is not known. This is usually known to develop along with previous surgical scars especially following Caesarean section and Hysterectomy.

Methods: Retrospective analysis of the patients operated for AWE was done. Data relating to age, symptomology, and previous caesarean section, relation to symptoms with the menstrual cycle, physical examination, surgical treatment and post-operative course was analyzed.

Results: 16 patients were operated during the study period of 3 years between September 2013-september 2016.The ages ranged between 20-35 years. Presences of local mass and cyclical pain during menstruation were the main symptoms. Ultrasonography was done in all the cases and CT abdomen was done in few cases (2) to know the exact depth of the mass and to differentiate from other diseases. Wide surgical excision was carried out in all cases.

Conclusions: There is definite relationship with AWE and caesarean sections in women.

Keywords: Abdominal wall, Endometrioma, Endometriosis, Surgical excision

\section{INTRODUCTION}

Endometriosis is defined as presence of functional endometrial tissue in location outside the endometrial cavity and uterine muscles that usually respond to hormonal stimulation. ${ }^{1}$ It was first described by Austrian pathologist Karl Freiherr von Rotitansky in $1860 .^{2}$ It is said to occur in $5-10 \%$ of the cases. Although it is more common in pelvic region, the extra pelvic occurrence of endometriosis is rare. AWE is still rare and is known to develop spontaneously and usually found at and around the site of scar of surgeries like hysterectomy, caesarean section, laparoscopy, tubal ligations and episiotomies. The exact incidence of AWE is unknown and the overall prevalence is around $0.01 \%-1 \%$ after caesarean section. ${ }^{3}$
AWE is often mistaken with some surgical conditions like abscess, stitch granuloma, lipoma or incisional hernia. One theory proposes the iatrogenic direct implantation and the other explains the transport mechanism. ${ }^{4}$

It is commonly seen within the peritoneum in the female pelvic cavity, ovaries, Douglas space and the uterosacral ligaments. It causes dysmenorrhea, dyspareunia, menstrual irregularity and infertility and there have been many theories described about the development of endometriosis and these are metaplasia, retrograde menstruation, venous and lymphatic metastasis and the mechanical transplantation within the incision area during surgery. ${ }^{5-7}$ The incidence of developing endometriosis in 
the scar area after the caesarean section varies between $0,03-3,5 \% .^{7,8}$

The common clinical presentation is presence of subcutaneous tumor and cyclical pain and swelling during the menstruation. But there may not be always mass in the complaints. In this condition, making the diagnosis is very difficult. Many methods such as computerized tomography and thin needle aspiration biopsy are used for diagnosis. ${ }^{7}$ Considering all the factors the present study was done with the following objectives to find out the risk factors for scar endometriosis and management of scar endometriosis.

\section{METHODS}

A Hospital based Prospective Interventional study was carried out in the Department of Obstetrics and Gynecology and Department of General Surgery at MallaReddy Institute of Medical Sciences a Tertiary care teaching hospital for a period of 3 years from September 2013 -September 2016. The study participants were all the women who had underwent previous LSCS and any other surgeries and presented with symptoms of mass and pain at the surgical site. During the study period, we enrolled 16 study participants.

A detailed history was taken with respect to Age, symptomology and relation of the symptoms with menstrual cycles, types and number of surgeries underwent in past, location of swelling. A detailed physical examination was done in all the study participants. For confirmation of diagnosis USG abdomen and CT abdomen was done. After diagnosis of abdominal wall endometriosis, the study participants underwent surgical management in form of wide excision and mesh repair in the department of General surgery. All patients were followed up and recurrence rate was nil in the study. Histological confirmation was done postsurgically. No case of malignancy was reported in the present study.

Before the start of the study all the study participants were informed about the purpose of the study. Informed and written consent was taken from all the study particiapants. Statistical analysis was done using Microsoft Excel software in form proportions.

\section{RESULTS}

Table 1 shows maximum number of study participants were in the age group of 20-30years $(87.5 \%)$ and $12.5 \%$ were in the age group of 30-35years.

Table 1: Age wise distribution of study participants.

\begin{tabular}{|lll|}
\hline Age (Years) & Frequency & $\%$ \\
\hline $20-30$ & 14 & 87.5 \\
\hline $30-35$ & 02 & 12.5 \\
\hline Total & 16 & 100 \\
\hline
\end{tabular}

Table 2: Distribution of study participants with the number of LSCS done.

\begin{tabular}{|lll|}
\hline LSCS & Frequency & $\%$ \\
\hline Single LSCS & 06 & 37.5 \\
\hline Two or More LSCS & 10 & 63.5 \\
\hline Total & 16 & 100 \\
\hline
\end{tabular}

Table 2 revealed near about $63.5 \%$ of the study particiapants underwent two or more LSCS in past and $37.5 \%$ had once LSCS.

Table 3: Distribution of study participants with types of surgeries.

\begin{tabular}{|lll|}
\hline Surgeries & Frequency & $\%$ \\
\hline LSCS & 14 & 87.5 \\
\hline Other than LSCS & 02 & 12.5 \\
\hline Total & 16 & 100 \\
\hline
\end{tabular}

Table 3 shows majority of the study participants $(87.5 \%)$ had underwent LSCS as major surgery compared to other surgeries $(12.5 \%)$.

Table 4: Distribution of study participants with presenting symptom.

\begin{tabular}{|lll|}
\hline Presenting symptom & Frequency & $\%$ \\
\hline Mass & 16 & 100 \\
\hline Pain & & \\
\hline Cyclical & 10 & 63.5 \\
\hline Non-cyclical & 06 & 37.5 \\
\hline
\end{tabular}

In Table 4 among all the study participants mass and pain was the main presenting symptom. Those who were having pain among them $63.5 \%$ of them had cyclical pain and $37.5 \%$ had non-cyclical pain.

Table 5: Distribution of study participants with location of mass.

\begin{tabular}{|lll|}
\hline Location of the mass & Frequency & $\%$ \\
\hline Under the scar & 13 & 81.25 \\
\hline In the scar & 03 & 18.75 \\
\hline Total & 16 & 100 \\
\hline
\end{tabular}

In Table 5, it was found that $81.25 \%$ of the study participants had mass under the scar and $18.75 \%$ had mass in the scar.

Table 6: Diagnostic tool to detect the mass.

\begin{tabular}{|lll|}
\hline Diagnosing Tool & Frequency & $\%$ \\
\hline Ultrasonogram (Abdomen) & 14 & 87.5 \\
\hline CT (Abdomen) & 02 & 12.5 \\
\hline Total & 16 & 100 \\
\hline
\end{tabular}

Table 6 shows the mass was detected in $87.5 \%$ was doing ultrasonography of abdomen and in $12.5 \%$ of study 
participants CT Abdomen was required to find out the mass.

After wide excision of the scar endometriosis, the patients were followed every 6 months for a period of 1 year so check for recurrence. There was no recurrence seen. Histopathological report showed no malignancy.

\section{DISCUSSION}

Maximum number of study participants were in the age group of $20-30$ years $(87.5 \%)$ and $12.5 \%$ were in the age group of 30-35years. In another study $91 \%$ of the study participants were in the age group of 25-35 years. ${ }^{9}$ Near about $63.5 \%$ of the study participants underwent two or more LSCS in past and $37.5 \%$ had once LSCS. Majority of the study participants $(87.5 \%)$ had underwent LSCS as major surgery compared to other surgeries $(12.5 \%)$. The study findings were similar with other study were near about $82 \%$ had LSCS as major surgery. ${ }^{10}$ LSCS considered as main risk factor for the formation of scar endometriosis which is similar to present study. ${ }^{10}$

Among all the study participants mass and pain was the main presenting symptom. Those who were having pain among them $63.5 \%$ of them had cyclical pain and $37.5 \%$ had non-cyclical pain. In another study done by LathaLakshmi et al, cyclical pain was seen in $57 \%$ of the study participants. It was found that $81.25 \%$ of the study participants had mass under the scar and $18.75 \%$ had mass in the scar were as in another study $96 \%$ of the study participants were having abdominal mass in the scar which is more than the present study. ${ }^{9}$ In another study mass in the scar was seen in $63 \%$ of the study participants \& $73.8 \%$ presented with abdominal pain. ${ }^{10}$ In another study $80 \%$ of the study participants had painful mass at the site of scar. ${ }^{10}$ The mass was detected in $87.5 \%$ by doing ultrasonography of abdomen and in $12.5 \%$ of study participants CT Abdomen was required to find out the mass. In another study mass was detected by ultrasonography in $34 \%$ of study participants which is less than present study and $40 \%$ of them CT scan was used as main diagnostic method. ${ }^{10}$ In another also wide excision of the scar endometriosis was one. ${ }^{9}$ After wide excision of the scar endometriosis, the patients were followed every 6 months for a period of 1 year so check for recurrence. There was no recurrence seen. Histopathological report showed no malignancy.

\section{CONCLUSION}

Although AWE is a rare disease, it can occur after the gynecological and obstetrics procedures. There is a clearcut relationship between Caesarean section and AWE. Wide excision of the tumour should be attempted in order to avoid recurrence.

Funding: No funding sources

Conflict of interest: None declared

Ethical approval: The study was approved by the Institutional Ethics Committee

\section{REFERENCES}

1. Williams HE, Barsky S, Storino W. Umbilical endometrioma (silent type). Arch Dermatol. 1976;112(10):1435-6.

2. Benagiano G, Drosens I. The history of endometriosis: identifying the disease. Hum Repord. 1991;6(7):963-8.

3. Dwivedi AJ, Agrawal SN, Silva YJ. Abdominal will endometriomas. Dig Dis Sci. 2002;47:456-61.

4. Ding Y, Zhu J. A retrospective review of abdominal wall endometriosis in Shanghai, China. Int J Gynecol Obstet. 2013;121(1):41-44.

5. Witz CA. Current concepts in the pathogenesis of endometriosis. Clin Obstet Gynecol. 1999;42:56685 .

6. Zafrakas M, Tarlatzis BC, Streichert T, Pournaropoulos F, Wölfle U, Smeets SJ. Genomewide microarray gene expression, array- CGH analysis, and telomerase activity in advanced ovarian endometriosis: A high degree of differentiation rather then malignant potential. Int $\mathrm{J}$ Mol Med 2008;21:335-44.

7. Nominato NS, Prates LFVS, Lauar I, Morais J, Maia L, Geber S. Scar endometriosis: a retrospective study of 72 patients. Rev Bras Gynecol Obstet. 2007;29(8):423-27.

8. Honore GM. Extrapelvic endometriosis. Clin Obstet Gynecol. 1999;42:699-711.

9. Lakshmi L, Londhe V, Tejovathy K, Varghese L, Visali J, Kekre A. Abdominal wall endometriosis: accuracy of the diagnostic triad. Int $\mathrm{J}$ Reprod Contracept Obstet Gynecol. 2015;4(5):1417-21.

10. Ecker AM, Donnellan NM, Shepherd JP, Lee TT. Abdominal wall endometriosis: 12 years of experience at a large academic institution. Am J Obstet Gynecol. 2014;211:363-5.

Cite this article as: Nalini YL, Puvvala MK,

Chandra AS, Rajalingam. A prospective study of abdominal wall endometriomas: a review of 16 cases. Int J Reprod Contracept Obstet Gynecol 2017:6:2784-6. 